\title{
Gut microbiota influence in type 2 diabetes mellitus (T2DM)
}

\author{
A. L. Cunningham ${ }^{1,2^{*}}\left(\mathbb{D}\right.$, J. W. Stephens ${ }^{1,2}$ and D. A. Harris ${ }^{1,2}$
}

\begin{abstract}
A strong and expanding evidence base supports the influence of gut microbiota in human metabolism. Altered glucose homeostasis is associated with altered gut microbiota, and is clearly associated with the development of type 2 diabetes mellitus (T2DM) and associated complications. Understanding the causal association between gut microbiota and metabolic risk has the potential role of identifying susceptible individuals to allow early targeted intervention.
\end{abstract}

Keywords: Gut microbiota, Type two diabetes mellitus

\section{Background}

The global prevalence of type 2 diabetes mellitus (T2DM) is projected to grow beyond 700 million patients by 2045 [1], at a cost to society of greater than two trillion US dollars [2]. The World Health Organisation (WHO) and the United Nations (UN) have made T2DM prevention a top health priority $[3,4]$. One in fifteen individuals in the United Kingdom (UK) has a diagnosis of diabetes, of which T2DM accounts for around 90\%, a current cohort of greater than three million people. Population estimations suggest one million patients already suffer from undiagnosed T2DM. Of these cases, $60 \%$ are considered preventable through lifestyle and dietary intervention [5]. Obesity, central adiposity and body mass index (BMI) play a pivotal role in the pathophysiology of T2DM, a chronic metabolic disease characterised by hyperglycaemia and associated with insulin resistance and/or insufficient pancreatic insulin production [6]. Unrecognised or suboptimal T2DM may lead to both micro- and macrovascular complications associated with hypertension, renal failure, susceptibility to infection, limb amputations and blindness with their subsequent disability.

*Correspondence: cunninghamal@doctors.org.uk

1 Department of Surgery, Swansea Bay University Health Board, Singleton Hospital, Swansea SA2 8QA, Wales

Full list of author information is available at the end of the article

\section{Microbiota}

In 2001, Joshua Lederberg, a former Nobel Prize winner, first defined the 'human microbiome' as an ecological community of commensal, symbiotic and pathogenic microorganisms that collectively share our body space [7]. Human health is strongly influenced by microbiota that are co-habiting with our body [8]. An adult human is colonised by approximately 100 trillion microbes found predominantly in the gastrointestinal tract (GIT), of which the largest population resides in the colon.

The majority of bacterial species cannot be cultured, however, the advancement of microbial analysis techniques and the use of rodent models has enabled the investigation of the role of gut microbiota in the pathogenesis of T2DM. Although rodents and humans differ in certain aspects of their physiology, animal models provide valuable opportunities to conduct investigations that cannot be undertaken in humans [9]. The vast majority of gut microbiota belong to four main families (phyla):-Firmicutes, Bacteroidetes, Proteobacteria and Actinobacteria [10-12]. Other smaller but relevant phyla include the Verrucomicrobia and Fusobacteria [13]. Under normal physiological conditions, Firmicutes make up the greatest proportion of the gut microbiota (64\%), followed by the Bacteroidetes (23\%), Proteobacteria (8\%) and lastly Actinobacteria (3\%). Evidence suggests that gut microbiota can influence original author(s) and the source, provide a link to the Creative Commons licence, and indicate if changes were made. The images or other third party material in this article are included in the article's Creative Commons licence, unless indicated otherwise in a credit line to the material. If material is not included in the article's Creative Commons licence and your intended use is not permitted by statutory regulation or exceeds the permitted use, you will need to obtain permission directly from the copyright holder. To view a copy of this licence, visit http://creativecommons.org/licenses/by/4.0/. The Creative Commons Public Domain Dedication waiver (http://creativeco mmons.org/publicdomain/zero/1.0/) applies to the data made available in this article, unless otherwise stated in a credit line to the data. 
human health either directly or indirectly $[14,15]$ and that disruption to stable communities may increase the prevalence of pro-inflammatory conditions such as obesity, inflammatory bowel disease, T2DM, arthritis and cancer [16]. Both animal models and humans with T2DM have demonstrated compositional changes within their microbiota profiles, which is most apparent at phylum and class levels [17, 18]. Confounding factors such as geographical location, culture, diet, health status and medication-use however have led to difficulty in identifying a 'common' microbiota profile associated with T2DM [19]. Complete bacterial counts and gene numbers are similar between T2DM patients and healthy controls $[17,20]$, but this diversity significantly declines in T2DM [21-23]. It is unlikely that a single microbe species plays a dominant role in determining the risk of T2DM [24].

Table 1 Microbiota community differences between participant cohorts

\begin{tabular}{ll}
\hline Participant cohort & Microbiota differences \\
\hline Normal physiological conditions [10-12] & $64 \%$ Firmicutes \\
& $23 \%$ Bacteroidetes \\
& $8 \%$ Proteobacteria \\
& $3 \%$ Actinobacteria \\
& $\downarrow$ Firmicutes \\
T2DM cohort [17] & $\uparrow$ Bacteroidetes \\
& $\uparrow$ B/F ratio \\
& $\uparrow$ Proteobacteria \\
& $\uparrow$ Firmicutes \\
T2DM cohort [23, 25] & $\uparrow$ Proteobacteria \\
& $\downarrow$ Bacteroidetes \\
& $\uparrow$ F/B ratio \\
& $\uparrow$ F/B ratio \\
Complicated T2DM vs uncomplicated T2DM & \\
[25] & No difference \\
T2DM cohort [26] &
\end{tabular}

Groups of subjects with and without T2DM have contrasting microbiota findings in terms of phyla composition (summarised in Table 1). Significantly lower relative abundances of Firmicutes, compared with a much higher proportion of Bacteroidetes and Proteobacteria has been reported in subjects with T2DM [17]. The Bacteroidetes to Firmicutes ratio (B/F ratio) is associated with increased plasma glucose following an oral glucose load [17]. Conversely, other research groups describe the abundance of Firmicutes and Proteobacteria as significantly increased, while Bacteroidetes is greatly reduced resulting in an enhanced $\mathrm{F} / \mathrm{B}$ ratio in T2DM compared to non-diabetic individuals $[23,25]$. Zhao et al., clarified the enhanced F/B ratio in T2DM subjects further, comparing complicated and uncomplicated T2DM cohorts and displaying an increased F/B ratio in favour of the complicated cohort, as expected [25]. Other groups have found no significant differences in microbiota [26]. Opportunistic pathogens are frequently described in T2DM microbiota communities including the species Bacteroides caccae, Clostridium hathewayi, Clostridium ramosum, Clostridium symbiosum, Eggerthella lenta and Escherichia coli $[18,26,27]$.

Specific genera with relatively high abundances in T2DM patients have also been identified. See Table 2 for summary. These include Blautia, Coprococcus, Sporobacter, Abiotrophia, Peptostreptococcus, Parasutterella and Collinsella $[25,26,28]$.

Butyrate producing microbes are particularly depleted in patients diagnosed with T2DM specifically the Clostridiales order, including the genera Ruminococcus and Subdoligranulum, and the species Eubacterium rectale, Faecali prausnitzii, Roseburia intestinalis and Roseburia inulinivorans [18, 21-23, 27]. Butyrate is well understood to benefit host homeostasis and will be discussed in further detail later in the review. The genera

Table 2 Individual microbiota differences in T2DM cohorts

\begin{tabular}{ll}
\hline Patient cohort & Microbiota findings \\
\hline $\operatorname{T2DM}[18,26,27]$ & $\uparrow$ opportunistic pathogens \\
& Bacteroides caccae, Clostridium hathewayi, Clostridium ramosum, Clostridium symbiosum, \\
& $\quad$ Eggerthella lenta, Escherichia coli \\
& $\uparrow$ Blautia, Coprococcus, Sporobacter, Abiotrophia, Peptostreptococcus, Parasutterella, Collinsella \\
T2DM $[24,26,28]$ & $\downarrow$ butyrate-producing microbes \\
T2DM $[18,21-23,27,120]$ & $\quad$ Eubacterium rectale, Faecali prausnitzii, Roseburia intestinalis, Roseburia inulinivorans, Rumino- \\
& $\quad$ coccus and Subdoligranulum \\
& $\downarrow$ Bacteroides, Prevotella, Bifidobacterium \\
T2DM $[23,25,34,35]$ & $\uparrow$ Lactobacillus \\
T2DM $[20,23,35]$ & $\downarrow \times 5$ clostridium species \\
& $\downarrow$ Akkermansia \\
T2DM $[25]$ & $\downarrow$ Akkermansia, Clostridium \\
Pre-diabetic $[43]$ & $\uparrow$ Ruminococcus, Streptococcus \\
&
\end{tabular}


Bacteroides, Prevotella and Bifidobacterium are found in significantly less numbers in T2DM patients $[23,25,33$, 34 . The genus Bifidobacterium is known to provide significant health benefits including the ability to improve intestinal permeability thereby lowering circulating levels of endotoxin and reducing systemic inflammation. This correlates with the improvement of host glucose tolerance and glucose-induced insulin secretion, and reduces inflammation [35-37].

A female European T2DM cohort displayed much greater numbers of the Lactobacillus species and a decline in the abundance of five Clostridium species [20]. Similar conclusions were also reported in two other studies [23, 34]. An increase in the population of the genus Lactobacillus correlates positively with lower fasting glucose levels and improved glycated haemoglobin (HbA1c) levels. Both species have no relationship with BMI [20]. Supplementing diabetic rodents with strains of the species Clostridium butyricum led to an improvement in circulating glucose levels, decreased systemic insulin resistance and inflammation, increased mitochondrial metabolism and a significant reduction in gut disruption [38].

The species Akkermansia muciniphila and Faecali prausnitzii appear to provide protection against the development of T2DM [27, 39, 40]. The genus Akkermansia plays a critical role in maintaining the integrity of the mucin layer and reducing inflammation [41]. Mucins are large, highly glycosylated proteins that partake in luminal protection of the GIT leading to a reduction in bacterial translocation and improving the storage of fat, adipose tissue metabolism and glucose homeostasis [41]. T2DM patients display significantly lower levels of Akkermansia [25]. Supplementing rodents with oligofructose (resulting in a secondary increase in Akkermansia) or direct treatment with Akkermansia improves their overall metabolic status [41]. Initiating T2DM treatment also appeared to directly initiate an increase in the abundance of Faecali prausnitzii, a secondary reduction in systemic inflammation and an improvement in insulin resistance [27]. Patients with pre-diabetes also demonstrate similar findings in their microbiota communities including a decrease in microbial diversity; depletion in the numbers of the genera Akkermansia and Clostridium; and increases in Ruminococcus and Streptococcus [42].

If a 'common' microbiota profile can be identified for T2DM, it could be possible to utilise microbial biomarkers alongside clinical parameters in a machine learning prediction model to distinguish patients at risk of T2DM with reliable diagnostic accuracy. Secondly, if this model proves successful, the selected microbial biomarkers could be used to monitor patients' glycaemic control and the introduction of new therapeutics.

\section{Type 1 diabetes mellitus}

Type 1 diabetes mellitus (T1DM) is a cellular-mediated autoimmune disease in which the destruction of pancreatic $\beta$-cells causes insulin deficiency resulting in hyperglycaemia and a potential for ketoacidosis. Autoimmune destruction of $\beta$-cells has strong genetic predispositions and are also related to environmental constituents that are still poorly understood $[43,44]$. The development of T1DM has been linked to aberrant intestinal microbiota, microbial-induced butyrate production, a disrupted intestinal mucosal barrier, and altered mucosal immunity $[45,46]$.

Currently there are several large prospective epidemiological studies in T1DM children aiming to identify and investigate environmental causes. The Environmental Determinants of Diabetes in the Young (TEDDY) study is the largest, with the aim of following several thousand newborns with a genetic predisposition for T1DM or a first-degree relative with T1DM [47]. Initial analysis has demonstrated that the presence of five bacterial genera is associated with the early development of T1DM, the genus Parabacteroides being the most significant. Secondly, eleven bacterial genera were depleted in the T1DM cohort, including four unclassified Ruminococcaceae, Lactococcus, Streptococcus and Akermansia [48].

In the islet autoimmunity (IA) case-control cohort, healthy controls contained higher levels of the species Lactobacillus rhamnosus and Bifidobacterium dentium, whereas IA cases had higher abundances of Streptococcus mitis/oralis/pneumoniae species [47]. A reduction in bacterial pathways for the production of short-chain fatty acids (SCFAs) such as butyrate in children who developed islet autoantibodies or T1DM were observed [47]. The relevance of the SCFAs is discussed in detail later in the review. Modifying the microbiota community is an interesting possibility in order to prevent T1DM development. Results from the TEDDY study demonstrated a decrease in islet autoimmunity in children given probiotics in early infancy [49]. Further studies are ongoing, however there is still a considerable lack of literature positively connecting microbiota dysbiosis as a predictor in the pathogenesis of T1DM [50].

\section{Medication induced changes in gut microbiota composition}

Gut microbial composition is highly variable between individuals and is continuously modified by endogenous and exogenous factors [51]. Geographic and environmental factors such as diet, illness, lifestyle, hygiene and medications can contribute to changes [52-54]. Antibiotic treatments have the ability to disrupt the gut microbiota community for several years after administration [55]. A population-wide case-control study performed 
in Scandinavia illustrated a strong association between antibiotic exposure and the development of subsequent T2DM. A relationship between T2DM diagnosis and the number of antibiotic prescriptions was also observed [56]. Further detailed work is required to establish association or causation. It is possible that antibiotics may predispose patients to the development of T2DM, however patients at-risk of T2DM may be more susceptible to illness in the years prior to diagnosis [56]. Vrieze et al., studied the effects of antibiotic treatment on the gut microbiota and the resulting effect on metabolic parameters in patients with obesity and insulin resistance. Vancomycin significantly lowered microbial diversity, decreased the abundance of Firmicutes, improved the numbers of Proteobacteria, particularly the genus Lactobacillus and decreased peripheral insulin sensitivity [57].

Glucose lowering medication including the biguanides, alpha-glucosidase inhibitors, incretin-based drugs, glucagon-like peptide 1 (GLP-1) receptor agonists, dipeptidyl peptidase-4 inhibitors and thiazolidinediones can all influence the gut microbiota [58]. Metformin is one of the most widely prescribed oral medications for patients with T2DM and does not intentionally modify gut microbiota. However, there is growing evidence to indicate that some effects may be enhanced by the microbiota [59, 60]. Metformin increases the relative abundance of the genera Akkermansia, Bifidobacterium and Lactobacillus [59-61]. Other enriched genre associations include Bacteroides, Butyricoccus, Prevotella, Megasphaera and Butyrivibrio [60]. These particular microbiota all have the ability to produce SCFAs. Metformin treatment results in improved microbial diversity, rapid changes in gut microbiota composition and improves intestinal function by enhancing SCFA production, promoting the activity of endocrine cells, regulating bile acid (BA) turnover, and reducing endotoxemia [60]. Short-term metformin treatment is associated with significantly lowered abundance of the species Bacteroides fragilis resulting in secondary increases of BA glycoursodexoycholic acid (GUDCA) levels in the gut. GUDCA inhibits intestinal farnesoid $X$ receptor (FXR) signalling leading to an improvement in glucose tolerance. Reintroducing Bacteroides fragilis reverses the improvements seen in glucose metabolism with metformin usage [62]. Other diabetic medications have not been as widely scrutinised as metformin treatment. Glibenclamide has only minor effects on gut microbiota alpha diversity. It increases the relative abundance of the family Paraprevotellaceae and Prevotella species [63]. Neither dapagliflozin or gliclazide have been shown to alter gut microbiota in T2DM patients to any significant extent when used in combination with metformin [64]. In high-fat dietary fed (HFD) rodents, liraglutide reduces gut microbial diversity and lowers the abundance of the phyla Bacteroidetes, Proteobacteria and Actinobacteria [65]. Decreases in the relative abundance of all obesity-related phylotypes (the genera Romboutsia and Ruminiclostridium, and the family Erysipelotrichaceae) were also noted, accompanied with an enrichment in the lean-related genre Blautia and Coprococcus [66]. Patients receiving GLP-1 agonists in combination with metformin have higher abundances of the genus Akkermansia than those on single treatment liraglutide [67].

\section{Gut microbiota impact on glucose and insulin metabolism}

Gut microbiota have the ability to alter host glucose homeostasis through multiple mechanisms including: the production of metabolites during fermentation and their resulting secondary effects; activation of inflammatory cascades leading to the release of cytokines; disrupting the permeability of the intestinal mucosal barrier allowing the influx of toxins; and direct signalling action through incretin secretion. These mechanisms have been discussed in great detail elsewhere, but we will summarise the main influencing factors below [68]. T2DM patients demonstrate an enrichment in their membrane transport of sugars, branched chain amino acids (BCAA) transportation, methane metabolism, xenobiotic degradation and metabolism, and sulphate reduction. The same cohort displayed reduced levels of bacterial chemotaxis, flagellar assembly, butyrate biosynthesis and metabolism of cofactors and vitamins [18]. Figure 1 provides a diagrammatic summary.

\section{Gut microbiota metabolites}

SCFAs, BCAAs, succinate, indole and imidazole are all microbial metabolites produced during anaerobic fermentation in the gut and act as central components in microbe-to-host signalling pathways [69, 70]. These metabolites are predominantly produced from microbiota genera such as Akkermansia, Prevotella, Ruminococus, Coprococcus, Faecalibacterium, Eubacterium, Roseburia, Clostridium, Bacteroides, Lactobacillus, Streptococcus, Propionibacterium and Fusobacterium [71-73]. As discussed earlier, the majority of these particular microbiota are depleted in patients with T2DM.

Butyrate, acetate and propionate are the most abundant SCFAs produced by intestinal fermentation of dietary fibre [74, 75]. Acetate and propionate are mostly produced by the phylum Bacteroidetes, while butyrate is produced by the Firmicutes [76]. SCFAs are directly utilised as an energy source by the intestinal mucosal cells or transferred to the systemic circulation to generate an important source of energy for the host and have the ability to behave as signaling molecules [74]. 


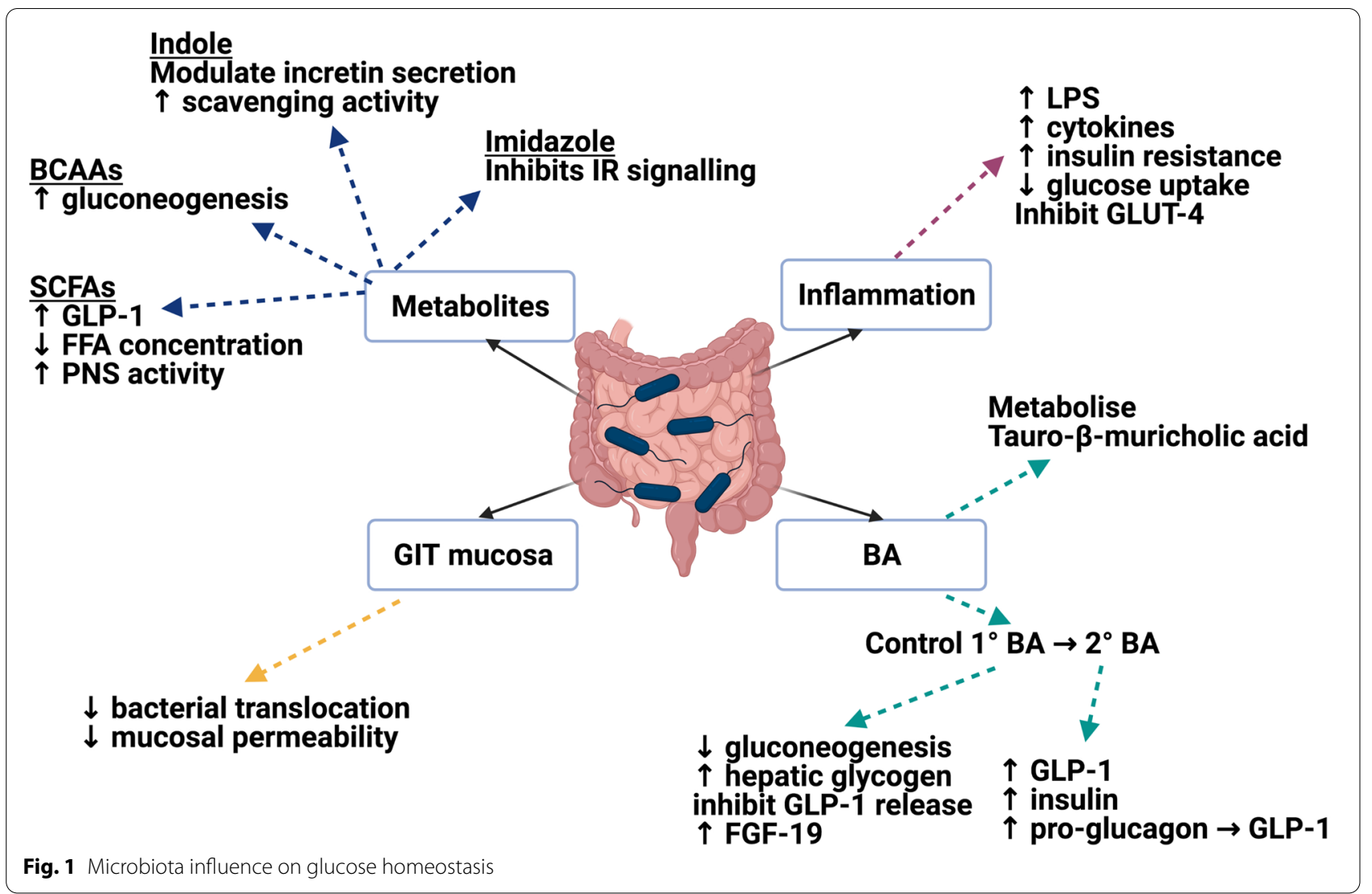

SCFAs strongly influence glucose metabolism through the coupling action with selected G-proteincoupled receptors (GPRs). These are predominantly expressed in adipose tissue, the intestine, and immune cells. GPR43 and GPR119 stimulation promotes the secretion of the incretin GLP-1 from enteroendocrine L-cells [77-79]. GLP-1 intensifies glucose-induced insulin release from $\beta$-cells, suppresses glucagon secretion, protects $\beta$-cells from apoptosis, promotes $\beta$-cell proliferation and prolongs intestinal transit time [80].

Stimulation of the receptor GPR41 by butyrate and propionate has the ability to induce intestinal gluconeogenesis through two different mechanisms of action. Firstly, by acting as a GPR41 agonist which enhances intestinal gluconeogenesis gene expression and secondly through a gut-brain neural circuit involving GPR41 [81].

SCFAs can also directly impact hepatic glucose metabolism, decreasing glycolysis and gluconeogenesis, increasing glycogen synthesis and lowering plasma fatty acid concentration [29, 82]. SCFAs have the ability to activate parasympathetic activity subsequently increasing appetite and promoting glucose-stimulated insulin secretion [83].
SCFAs have been demonstrated to enhance glucose uptake peripherally, by increasing the expression of glucose transporter type 4 (GLUT4), through the action of AMP-activated protein kinase (AMPK) activity. Secondly, in skeletal muscle, SCFAs have the capability of reducing glycolysis resulting in secondary accumulation of glucose-6-phosphate leading to greater glycogen synthesis [84, 85].

Acetate, the most abundant SCFA, is taken up by the intestinal epithelium, transported to the liver via the portal vein, and eventually distributed to peripheral tissues where it is metabolised [86]. Systemic acetate has the capability of crossing the blood-brain barrier where it can activate acetyl-CoA carboxylase leading to the enhancement of the expression of neuropeptides which induces hypothalamic neuronal activation and suppresses appetite [87].

Butyrate is the principal substrate and energy source for colonocytes providing at least $60-70 \%$ of colonic mucosa energy requirements, essential for their proliferation and differentiation $[29,30]$. Butyrate is important in maintaining colonic epithelium homeostasis mainly by utilising its anti-inflammatory properties, thereby preventing the production of reactive oxygen and nitrogen 
species generated in oxidative stress [31, 88]. Sanna et al. reported that the abundance of butyrate-producing microbiota is associated with an improved insulin response during an oral glucose tolerance test (an indication of improved $\beta$-cell function) [89].

Intestinally produced propionate is a known preferred precursor for gluconeogenesis of which approximately $50 \%$ is utilised in this manner $[69,90]$. Propionate enters the tricarboxylic acid (TCA) cycle and is converted into succinyl-CoA via three successive reactions. The resulting succinyl-CoA re-enters the TCA cycle and is converted into oxaloacetate, the gluconeogenesis precursor [91].

Increased intestinal propionate delivery has been associated with enhanced $\beta$-cell function and glucosestimulated insulin secretion that was independent of alterations in GLP-1 levels. Propionate also provided protection for the human islets through the direct inhibition of apoptosis induced by inflammatory cytokines [92]. Lastly, supplementing overweight patients with intestinal propionate resulted in reduced energy intake and adiposity, and intensified plasma levels of peptide YY (PYY) and GLP-1 [93].

It is possible to improve T2DM control through the introduction of a high-fibre diet. Encouraging patients to ingest a high-fibre diet has been demonstrated to improve the quantities of SCFA-producing microbiota, leading to a reduction in HbA1c levels facilitated by an increase in the production of GLP-1 [94]. Patients receiving a highfibre diet had greater reductions in HbA1c levels and a higher proportion of this cohort achieved adequate glycaemic control $(\mathrm{HbA} 1 \mathrm{c}<7 \%)$ compared with the control group [94]. A further clinical study [95], advising the ingestion of a Mediterranean diet (rich in fibre), has also reported improvements in glucose and insulin sensitivity in individuals with high cardiometabolic risk. Greater postprandial plasma butyrate concentrations were found associated with increases in the abundance of the species Intestinimonas butyriciproducens and Akkermansia muciniphila. Of note, the butyrate concentrations directly correlated with postprandial insulin sensitivity, evaluated by the oral glucose insulin sensitivity (OGIS) model [95].

The bacterial fermentation of dietary fibre produces large amounts of succinate that improves glycaemic control through the activation of intestinal gluconeogenesis [96], which is also true of the SCFAs butyrate and propionate [81,97]. Increases in a small number of essential amino acids including the BCAAs and the aromatic amino acids have been reported to be associated with a five-fold increased risk of developing T2DM in the future [98]. Raised plasma levels of BCAAs has also been demonstrated to be characteristic of insulin resistance, correlating with two specific bacterial species, Prevotella copri and Bacteroides vulgatus [31]. Insulin-resistant patients display enriched BCAA biosynthesis and are found to be deprived of genes encoding bacterial inward transporters for these particular amino acids [31]. In rodents, it was demonstrated that the species Prevotella copri can induce insulin resistance, exacerbate glucose intolerance and intensify BCAA levels [31].

Indolepropionic acid, a metabolite generated by bacterial aromatic amino acid catabolism is highly correlated with dietary fibre intake and appears to reduce the risk of developing T2DM. It provides potent radical scavenging activity raising the suggestion that it may provide protection for the pancreatic $\beta$-cell from damage associated with metabolic and oxidative stress [32]. It may also be involved in the modulation of incretin secretion from enteroendocrine L-cells by inhibiting voltage-gated potassium channels, triggering GLP-1 secretion $[99,100]$.

Imidazole propionate, produced from the degradation of histidine by gut microbiota, impairs the ability of cells to correctly respond to insulin by acting as an inhibitor of the intracellular insulin receptor signalling cascade [101].

\section{Bile acids}

BAs are steroid carboxylic acids derived primarily from cholesterol through the action of the rate-limiting enzyme $7 \alpha$-hydroxylase (CYP7A1), which are then conjugated to glycine or taurine before being secreted in bile. Greater than $95 \%$ are reabsorbed in the terminal ileum and colon through the enterohepatic circulation $[102,103]$. The main function of BAs is the digestion and absorption of lipids and lipid-soluble vitamins within the small intestine. Lactobacillus, Bifidobacterium, Enterobacter, Bacteroides and Clostridium are the main gut microbiota that influence BA synthesis, modification and signalling. They have the ability to control the conversion of primary BAs (cholic acid and chenodeoxycholic acid) into secondary BAs (deoxycholic and lithocholic acids), through the process of deconjugation and the ability to metabolise the naturally occurring FXR antagonist tauro$\beta$-muricholic acid [102-105]. In turn, BAs contribute towards intestinal homeostasis by suppressing bacterial colonisation and growth in the intestine because of their strong antimicrobial activity [106]. In addition to roles in intestinal digestion and absorption, BAs have the ability to exert important metabolic effects acting as hormones.

BAs can adjust glucose metabolism through receptor coupling signalling using both the FXR and G-protein receptor 5 (TGR-5) [107]. FXR coupling is only possible by primary BAs and has the ability to reduce gluconeogenesis, promote hepatic glycogen production, inhibit the release of GLP-1 and stimulate the secretion of fibroblast growth factor (FGF-19) from the ileum. FXR 
signaling inhibits the expression of gluconeogenic genes, such as those encoding phosphoenolpyruvate carboxykinase, fructose-1, 6-biphosphatase-1, and glucose-6-phosphatase [108]. FGF-19 regulates BA synthesis by reducing the expression of CYP7A1, inhibiting glucose production and inducing glycogen synthesis. TGR-5 (bound only by secondary BAs) coupling results in GLP-1 secretion from intestinal L-cells, increases glucose-stimulated insulin release and promotes the conversion of pro-glucagon to GLP-1. In skeletal muscles and brown adipose tissue, BATGR5 signaling encourages thyroxine (T4) conversion to the biologically active triiodothyronine (T3) through the stimulation of type 2 iodothyronine deiodinase, resulting in greater energy expenditure. Coupling of both receptors encourages the production of insulin from pancreatic $\beta$-cells [102, 109-111].

Evidence suggests that manipulation of the BA pool using BA sequestrants improves glycaemic control in patients with T2DM. BA sequestrants bind BAs in the intestine to form a nonabsorbable complex resulting in interruption of the enterohepatic circulation. The mechanisms underlying the blood glucose-lowering effect of BA sequestrants are poorly understood, but are believed to involve the disruption of the BA pool composition, enhancing hepatic glucose metabolism, increasing the release of incretin hormones and inducing alterations in gut microbiota composition $[112,113]$.

\section{Gastrointestinal barrier function}

The intestinal mucosal lining acts as a preventative barrier to undesirable interactions with potentially harmful substances and plays an integral role in the regulation of the immune system [114]. T2DM is well understood to have significantly enhanced permeability in the gut allowing for the translocation of bacteria across the gut epithelium resulting in host metabolic endotoxaemia triggering low-grade inflammation. The resulting effects can initiate $\beta$-cell destruction and insulin resistance [50, 115]. As already described, the genera Faecalibacterium, Roseburia and Bifidobacterium are all recognised in their abilities to provide protection against bacterial translocation and reduce intestinal permeability $[116,117]$. T2DM patients are known to have depleted abundances of these particular microbiota.

\section{Inflammatory response}

T2DM is characterised by a state of chronic low-grade inflammation combined with abnormal expression and production of numerous inflammatory mediators [118120]. Individuals with T2DM have reduced amounts of butyrate-producing microbiota, encouraging low-grade inflammation in the gut $[21,121]$. Gut microbiota activate host inflammation and insulin resistance through the activity of lipopolysaccharide (LPS), an essential component of Gram-negative bacteria cell walls [35, 122, 123]. Bacterial fragments and LPS are recognised by innate toll-like receptors (TLRs), particularly TLR4 , triggering the activation of the intracellular signalling pathway NF- $\mathrm{KB}$ and the release of pro-inflammatory cytokines [123-125]. LPS release also stimulates localised immune responses through high-affinity coupling with the NLRP3 inflammasome and NOD-like receptors (NLRs) expressed on macrophages and dendritic cells [126]. The activation of serum kinases (Jnk and IKK) in the inflammatory NF- $\mathrm{kB}$ cascade induces phosphorylation of the insulin receptor substrate (IRS) serine, worsening insulin resistance [52].

The release of pro-inflammatory cytokines disrupts glucose metabolism and insulin signalling. T2DM patients display elevated levels of TNF- $\alpha$, which is strongly associated with altered glucose tolerance, enhanced insulin resistance and islet dysfunction [127-129]. TNF- $\alpha$ has the capability to up-regulate the transcription of suppressor of cytokine signaling-3 (SOCS-3) which couples to tyrosine-960 of the insulin receptor preventing IRS-1 binding to the insulin receptor (IR). This then leads to the degradation of IRS-1 and the disruption of the insulin signalling pathway $[130,131]$.

Interleukin-1 (IL-1), an inflammatory cytokine of the interleukin family has the potential to reduce the expression of IRS-1, inhibit the translocation of the GLUT-4 to the plasma membrane and reduce insulin-stimulated glucose uptake [132]. Recent work has illustrated that an IL-1 receptor antagonist (IL-1RA) and IL- $1 \beta$-specific antibody treatment improved glucose metabolism and insulin secretion in T2DM patients [133, 134].

IL-6 has been identified as an independent predictor of T2DM [135]. It exerts long-term inhibition on gene transcription of IRS-1, GLUT4, and peroxisome proliferator-activated receptors (PPARs), as well as significantly reducing insulin-stimulated tyrosine phosphorylation and insulin-stimulated glucose transport [136].

\section{Prebiotics, probiotics and synbiotics}

Prebiotics, probiotics and synbiotics are attractive dietary adjuncts with the capability of manipulating the intestinal microbiota composition with the aim of creating an environment for the improvement in glucose metabolism. A growing literature base supports the clinical usage of the addition of prebiotics, probiotics and synbiotics for improving glycaemic control in patients diagnosed with T2DM [137, 138]. It is challenging however, due to the heterogeneity between study methodology (study duration, quantity of supplement, patient demographics) which hinders study comparison and data remains limited by the poor availability of studies, relative small size 
of individual studies and the clear lack of microbiota data.

Probiotics are living microorganisms that, when administered in adequate quantities, confer benefits to an individual's health [139] whereas prebiotics are food components such as indigestible polysaccharides or fibre that beneficially affect the host by selectively stimulating the growth and/or activity of one or a limited number of intestinal microbiota [140]. Lastly, 'a mixture comprising live microorganisms and substrate selectively utilised by host intestinal microbiota to confer 'a host health benefit' is described as a synbiotic [141].

Evidence suggests that probiotics are able to improve the intestinal microbiota community leading to greater T2DM control with associated enhanced intestinal integrity, decreased circulating LPS, decreased endoplasmic reticulum stress and improved peripheral insulin sensitivity [142]. Tao et al., performed a meta-analysis focusing on the effects of probiotic supplementation on $\mathrm{HbA} 1 \mathrm{c}$ levels, fasting blood glucose (FBG) and insulin resistance in T2DM patients. A total of 15 randomised control trials (RCTs) involving 902 patients were included. The results showed that probiotics may reduce $\mathrm{HbA1c}$ levels $(p=0.02)$, FBG $(\mathrm{p}=0.003)$, and insulin resistance $(p<0.00001)$ from baseline [143]. As mentioned earlier, limited studies comment on microbiota alterations. Two studies mentioned microbiota analysis following probiotic addition and reported changes in bacterial composition. Andreasen et al. [144]., reported a significant enhancement in the abundance of the species Lactobacillus acidophilus from near non-detectable levels preintervention. Firouzi et al. [145], reported significant increases in the quantities of the genus Bifidobacterium (4.5 fold) and Lactobacillus species (twofold).

Prebiotic supplementation is associated with improved glycaemic control however as per with probiotic study reporting, heterogeneity in methodology is also vast resulting in inconclusive literature. Wang et al. [146]., published the most comprehensive meta-analysis to date, which included 33 RCTs involving 1346 participants spread across healthy, obese and T2DM cohorts. Focusing solely on the prediabetic and T2DM cohorts, compared with the control, the relative reduction of the FBG, HbA1c levels, fasting insulin concentration and insulin sensitivity was $7.15,7.00,16.58$, and $25.34 \%$ of their baseline values after supplementation [146]. A daily supplement dose greater than $10 \mathrm{~g}$ and for a minimum duration of 42 days was recommended for consistent improvement across the glycaemic indicators.

It is unclear whether the observed effects are related to gut microbiota modification or because of the greater availability of substrate for fermentation. There is a sustained lack of microbiota analysis across the literature directly attributed to the improvements in glucose levels. Birkeland et al. [147], demonstrated that six weeks addition of a prebiotic can produce a significant bifidogenic effect and improve faecal SCFA concentrations however no effect was seen on overall microbial diversity. Secondly, Pedersen et al. [148], showed that prebiotic supplementation can increase bacterial diversity, as assessed by the Shannon and inverse Simpson indices, and richness in T2DM patients. However, no statistical improvements in glucose control were observed after twelve weeks of dietary treatment.

Lastly, Sheth et al. [149]., introduced a synbiotic to sixty pre-hypertensive patients with T2DM (two species of Lactobacillus and Bifidobacterium each, one species of Streptococcus and yeast, and $300 \mathrm{mg}$ oligosaccharide). Increases in both the genera Lactobacillus (32.6\%) and Bifidobacterium (131.6\%) and a significant reduction in enteric pathogens (44.6\%) were reported following the intervention along with improvements in fasting blood glucose (3.3\%) and HbA1c levels (14\%).

There is increasing evidence that the addition of prebiotics, probiotics and synbiotics can improve glycaemic control. Detailed work is required in designing robust methodology to identify whether these positive changes are directly attributable to the modification of the intestinal microbiota and the complex metabolic mechanisms involved. Once this relationship is better understood, the potential to utilise these dietary additions in the management of T2DM can begin.

\section{Faecal microbiota transplantation}

Faecal microbiota transplantation (FMT) is the transfer of minimally manipulated pre-screened donor stool, into the GIT of an identified 'diseased' patient with the aim of correcting the dysbiotic state, increasing overall diversity and restore the functionality of the microbiota [150]. Currently, FMT is only recommended for the treatment of recurrent Clostridium difficile infection (rCDI) with resolution rates exceeding $89 \%$ [151]. There are a significant number of ongoing studies exploring other potential indications including T2DM. FMT is believed to have better potential than dietary supplements such as probiotics because FMT has the capability of transferring entire donor microbiota communities, including their metabolites, with the perceived enhanced capability to correct microbiota disruption over single microbial targets [152].

There is currently limited evidence for the use of FMT in T2DM but human studies investigating the clinical effects of FMT in patients with metabolic syndrome can be used to stimulate interest. Vrieze et al. [153], reported the improved insulin sensitivity of male recipients diagnosed with metabolic syndrome and the enhanced 
abundance of butyrate-producing intestinal microbiota (the species Roseburia intestinalis), six weeks after receiving allogenic microbiota. Secondly, a study reported that patients with metabolic syndrome, observed that HbA1c levels were significantly reduced after allogenic FMT, and was associated with changes in intestinal microbiota composition [154]. Reduced gene richness in participant baseline microbiota before allogenic FMT was related with improved clinical outcome. It should be mentioned that the clinical benefits in both studies deteriorated with time and there was considerable individual variability.

Further detailed work is required in order to explore the potential of FMT, particularly in metabolic disease (T2DM) such as identifying optimal donor microbiome characteristics; calculating appropriate dosing frequency and thresholds in the need for replenishing treatments in order to achieve longevity of microbiota engraftment; whether there is a requirement for recipient preparation; and lastly whether recipient host factors have the ability to modulate treatment efficacy. It is possible that manipulating the gut microbiota using techniques such as FMT might be an extremely promising therapeutic option in the management of T2DM.

\section{Conclusion: future direction}

T2DM is a complex multi-system disorder which can have life changing complications if not identified and treated appropriately. As described in this article, particular gut microbiota may contribute heavily to this development through the alteration of glucose metabolism pathways. As the T2DM population grows, this enables access to a vast number of patients for investigation. However, more meticulous work is required to disentangle a 'common' microbiota profile, given that these patients tend to be on multiple prescribed medications and have other related/unrelated comorbidities. This microbiota profile may be an individual or a collective group of gut microbiota but conclusive evidence is needed in order to assist the identification of the 'at-risk' population before the onset of disease.

Once a common profile is well understood, it will enable the exponential growth of microbiota targeted therapeutics in order to establish a strong evidence base on the metabolic effects of altering host microbiota. Treatment regimes that need to be thoroughly investigated include the use of prebiotics, probiotics and facilitated microbiota transfer (FMT), with the end goal of simplified early intervention in identified at-risk populations. This would reduce unnecessary secondary health complications with significant cost savings to the health service.

\section{Abbreviations}

AMPK: AMP-activated protein kinase; BA: Bile acid; BCAA: Branched chain amino acid; BMI: Body mass index; CYP7A1: Cholesterol 7 alpha-hydroxylase; FBG: Fasting blood glucose; FGF-19: Fibroblast growth factor; FMT: Faecal microbiota transplant; FXR: Farnesoid X receptor; GIT: Gastrointestinal tract; GLUT-4: Glucose transporter type 4; GLP-1: Glucagon-like peptide 1; GPR: G-protein receptor; GUDCA: Glycoursodexoycholic acid; HbA1c: Glycated haemoglobin; HFD: High fat diet; IA: Islet autoimmunity; IKK: Inhibitor of nuclear factor-KB kinase complex; IL-1: Interleukin 1; IL-1RA: Interleukin-1 receptor antagonist; IR: Insulin receptor; IRS: Insulin receptor substrate; JNK: C-Jun N-terminal kinase pathway; LPS: Lipopolysaccharide; NF-KB: Nuclear factor kappa light chain enhancer of activated B-cells; NLRs: NOD like receptors; NLRP3: Nucleotide-binding domain-like receptor protein 3; OGIS: Oral glucose insulin sensitivity; OGTT: Oral glucose tolerance test; PPARs: Peroxisome proliferator-activated receptors; PYY: Peptide tyrosine tyrosine; rCDI: Recurrent Clostridium difficile infection; RCT: Randomised clinical trial; SCFA: Short chain fatty acid; SOCS-3: Suppressor cytokine-3; T3: Triiodothyronine; T4: Thyroxine; TCA:Tricarboxylic acid; TEDDY: The Environmental Determinants of Diabetes in the Young study; TGR-5: G-protein receptor 5; TLRs: Toll-like receptors; T1DM: Type one diabetes mellitus; T2DM: Type two diabetes mellitus; TNF-a: Tumour necrosis factor alpha; UK: United Kingdom; UN: United Nations; WHO: World Health Organisation.

\section{Acknowledgements}

Figures have been produced using Biorender.com.

\section{Authors' contributions}

AC performed the relevant background/literature searches for the major construction of this review. DH and JS were major contributors in the editing of this paper. All authors read and approved the final manuscript.

\section{Funding}

The authors deny any source of funding for the development of this work.

\section{Availability of data and material}

Data sharing not applicable to this article as no datasets were generated or analysed during the completion of this review.

\section{Declarations}

Ethics approval and consent to participate

Not applicable.

\section{Consent for publication}

All authors consent to this publication.

\section{Competing interests}

The authors declare that they have no financial or non-financial competing interests.

\section{Author details}

${ }^{1}$ Department of Surgery, Swansea Bay University Health Board, Singleton Hospital, Swansea SA2 8QA, Wales. ${ }^{2}$ School of Medicine, Swansea University Medical School, Institute of Life Science 2, Swansea SA2 8QA, Wales.

Received: 9 April 2021 Accepted: 25 July 2021

Published online: 06 August 2021

\footnotetext{
References

1. International Diabetes Federation. IDF Diabetes Atlas, Ninth Edition. 2019. https://www.diabetesatlas.org/en/. Accessed 01 Mar 2021.

2. Bommer C, Sagalova V, Heesemann E, Manne-Goehler J, Atun R, Bärnighausen T, et al. Global economic burden of diabetes in adults: projections from 2015 to 2030. Diabetes Care. 2018;41(5):963-70.

3. World Health Organisation. Global Report on Diabetes. 2016. https:// www.who.int/publications/i/item/9789241565257. Accessed 01 Mar 2021.
} 
4. United Nations General Assembly. Political declaration of the high-level meeting of the general assembly on the prevention and control of non-communicable diseases. 2012. https://www.who.int/nmh/events/ un_ncd_summit2011/political_declaration_en.pdf. Accessed 01 Mar 2021.

5. : Diabetes UK, Facts and Stats (2019). https://www.diabetes.org.uk/ resources-s3/2019-02/1362B_Facts\%20and\%20stats\%20Update\% 20Jan\%202019_LOW\%20RES_EXTERNAL.pdf. Accessed 01 Mar 2021.

6. American Diabetes Association. Diagnosis and classification of diabetes mellitus. Diabetes Care. 2010;33(Suppl 1):S62-9. https://doi.org/10. 2337/dc10-S062.

7. Lederberg J, McCray A. Ome sweet omics - a genealogical treasury of words. Scientist. 2001;15(7):8.

8. Relman DA, Falkow S. The meaning and impact of the human genome sequence for microbiology. Trends Microbiol. 2001;9(5):206-8. https:// doi.org/10.1016/s0966-842x(01)02041-8.

9. Clavel T, Desmarchelier C, Haller D, et al. Intestinal microbiota in metabolic diseases: from bacterial community structure and functions to species of pathophysiological relevance. Gut Microbes. 2014;5(4):54451. https://doi.org/10.4161/gmic.29331.

10. Turnbaugh PJ, Ley RE, Hamady M, Fraser-Liggett CM, Knight R, Gordon JI. The human microbiome project. Nature. 2007:449(7164):804-10. https://doi.org/10.1038/nature06244.

11. Delzenne NM, Cani PD. Gut microbiota and the pathogenesis of insulin resistance. Curr Diab Rep. 2011;11(3):154-9. https://doi.org/10.1007/ s11892-011-0191-1.

12. Kootte RS, Vrieze A, Holleman F, et al. The therapeutic potential of manipulating gut microbiota in obesity and type 2 diabetes mellitus. Diabetes Obes Metab. 2012;14(2):112-20. https://doi.org/10.1111/j. 1463-1326.2011.01483.x

13. Blaut M. Ecology and physiology of the intestinal tract. Curr Top Microbiol Immunol. 2013;358:247-72. https://doi.org/10.1007/82_2011_192.

14. Clemente JC, Ursell LK, Parfrey LW, Knight R. The impact of the gut microbiota on human health: an integrative view. Cell. 2012;148(6):1258-70. https://doi.org/10.1016/j.cell.2012.01.035.

15. Kau AL, Ahern PP, Griffin NW, Goodman AL, Gordon JI. Human nutrition, the gut microbiome and the immune system. Nature. 2011:474(7351):327-36. https://doi.org/10.1038/nature10213.

16. Guarner F, Malagelada JR. Gut flora in health and disease. Lancet. 2003;361 (9356):512-9. https://doi.org/10.1016/S0140-6736(03)12489-0.

17. Larsen N, Vogensen FK, van den Berg FW, et al. Gut microbiota in human adults with type 2 diabetes differs from non-diabetic adults. PLoS ONE. 2010. https://doi.org/10.1371/journal.pone.0009085.

18. Qin J, LiY, Cai Z, et al. A metagenome-wide association study of gut microbiota in type 2 diabetes. Nature. 2012;490(7418):55-60. https:// doi.org/10.1038/nature11450.

19. He Y, Wu W, Zheng HM, et al. Regional variation limits applications of healthy gut microbiome reference ranges and disease models. Nat Med. 2018;24(10):1532-5. https://doi.org/10.1038/s41591-018-0164-x.

20. Karlsson FH, Tremaroli V, Nookaew I, et al. Gut metagenome in European women with normal, impaired and diabetic glucose control. Nature. 2013;498(7452):99-103. https://doi.org/10.1038/nature12198.

21. Forslund $K$, Hildebrand F, Nielsen T, et al. Disentangling type 2 diabetes and metformin treatment signatures in the human gut microbiota. Nature. 2015;528(7581):262-6. https://doi.org/10.1038/nature15766.

22. Zhang $F$, Wang $M$, Yang J, et al. Response of gut microbiota in type 2 diabetes to hypoglycemic agents. Endocrine. 2019;66(3):485-93. https://doi.org/10.1007/s12020-019-02041-5.

23. Sedighi M, Razavi S, Navab-Moghadam F, et al. Comparison of gut microbiota in adult patients with type 2 diabetes and healthy individuals. Microb Pathog. 2017;111:362-9. https://doi.org/10.1016/j.micpath. 2017.08.038.

24. Komaroff AL. The microbiome and risk for obesity and diabetes. JAMA. 2017;317(4):355-6. https://doi.org/10.1001/jama.2016.20099.

25. Zhao L, Lou H, Peng Y, Chen S, Zhang Y, Li X. Comprehensive relationships between gut microbiome and faecal metabolome in individuals with type 2 diabetes and its complications. Endocrine. 2019;66(3):52637. https://doi.org/10.1007/s12020-019-02103-8.

26. Lambeth SM, Carson T, Lowe J, et al. Composition, diversity and abundance of gut microbiome in prediabetes and type 2 diabetes. $J$
Diabetes Obes. 2015;2(3):1-7. https://doi.org/10.15436/2376-0949.15. 031.

27. Furet JP, Kong LC, Tap J, et al. Differential adaptation of human gut microbiota to bariatric surgery-induced weight loss: links with metabolic and low-grade inflammation markers. Diabetes. 2010;59(12):304957. https://doi.org/10.2337/db10-0253.

28. Zhang $X$, Shen $D$, Fang $Z$, et al. Human gut microbiota changes reveal the progression of glucose intolerance. PLoS ONE. 2013;8(8):e71108. https://doi.org/10.1371/journal.pone.0071108.

29. Canfora EE, Jocken JW, Blaak EE. Short-chain fatty acids in control of body weight and insulin sensitivity. Nat Rev Endocrinol. 2015;11(10):577-91. https://doi.org/10.1038/nrendo.2015.128.

30. Kelly CJ, Zheng L, Campbell EL, et al. Crosstalk between microbiotaderived short-chain fatty acids and intestinal epithelial HIF augments tissue barrier function. Cell Host Microbe. 2015;17(5):662-71. https:// doi.org/10.1016/j.chom.2015.03.005.

31. Pedersen HK, Gudmundsdottir V, Nielsen HB, et al. Human gut microbes impact host serum metabolome and insulin sensitivity. Nature. 2016;535(7612):376-81. https://doi.org/10.1038/nature18646.

32. de Mello VD, Paananen J, Lindström J, et al. Indolepropionic acid and novel lipid metabolites are associated with a lower risk of type 2 diabetes in the Finnish Diabetes Prevention Study. Sci Rep. 2017;7:46337. https://doi.org/10.1038/srep46337.

33. Wu X, Ma C, Han L, et al. Molecular characterisation of the faecal microbiota in patients with type II diabetes. Curr Microbiol. 2010;61 (1):69-78. https://doi.org/10.1007/s00284-010-9582-9.

34. Sato J, Kanazawa A, Ikeda F, et al. Gut dysbiosis and detection of "live gut bacteria" in blood of Japanese patients with type 2 diabetes. Diabetes Care. 2014;37(8):2343-50. https://doi.org/10.2337/dc13-2817.

35. Cani PD, Neyrinck AM, Fava F, et al. Selective increases of bifidobacteria in gut microflora improve high-fat-diet-induced diabetes in mice through a mechanism associated with endotoxaemia. Diabetologia. 2007:50(11):2374-83. https://doi.org/10.1007/s00125-007-0791-0.

36. Amar J, Chabo C, Waget A, et al. Intestinal mucosal adherence and translocation of commensal bacteria at the early onset of type 2 diabetes: molecular mechanisms and probiotic treatment. EMBO Mol Med. 2011;3(9):559-72. https://doi.org/10.1002/emmm.201100159.

37. O'Mahony D, Murphy S, Boileau T, et al. Bifidobacterium animalis AHC7 protects against pathogen-induced NF-kB activation in vivo. BMC Immunol. 2010;11:63. https://doi.org/10.1186/1471-2172-11-63.

38. Jia $L$, Li D, Feng $N$, et al. Anti-diabetic effects of clostridium butyricum CGMCC0313.1 through promoting the growth of gut butyrate-producing bacteria in type 2 diabetic mice. Sci Rep. 2017;7(1):7046. https://doi. org/10.1038/s41598-017-07335-0.

39. de Goffau MC, Luopajärvi K, Knip M, et al. Fecal microbiota composition differs between children with $\beta$-cell autoimmunity and those without. Diabetes. 2013;62(4):1238-44. https://doi.org/10.2337/db12-0526.

40. Depommier C, Everard A, Druart C, et al. Supplementation with Akkermansia muciniphila in overweight and obese human volunteers: a proof-of-concept exploratory study. Nat Med. 2019;25(7):1096-103. https://doi.org/10.1038/s41591-019-0495-2.

41. Everard A, Belzer C, Geurts L, et al. Cross-talk between Akkermansia muciniphila and intestinal epithelium controls diet-induced obesity. Proc Natl Acad Sci U S A. 2013;1 10(22):9066-71. https://doi.org/10. 1073/pnas.1219451110.

42. Allin $\mathrm{KH}$, Tremaroli V, Caesar R, et al. Aberrant intestinal microbiota in individuals with prediabetes. Diabetologia. 2018;61(4):810-20. https:// doi.org/10.1007/s00125-018-4550-1.

43. American Diabetes Association. 2. classification and diagnosis of diabetes: standards of medical care in diabetes-2020. Diabetes Care. 2020;43(Suppl 1):S14-31. https://doi.org/10.2337/dc20-S002.

44. American Diabetes Association. Diagnosis and classification of diabetes mellitus. Diabetes Care. 2014;37(Suppl 1):S81-90. https://doi.org/10. 2337/dc14-S081.

45. Vaarala O, Atkinson MA, Neu J. The, "perfect storm" for type 1 diabetes: the complex interplay between intestinal microbiota, gut permeability, and mucosal immunity. Diabetes. 2008;57(10):2555-62. https://doi.org/ $10.2337 / \mathrm{db} 08-0331$

46. Brown CT, Davis-Richardson AG, Giongo A, et al. Gut microbiome metagenomics analysis suggests a functional model for the 
development of autoimmunity for type 1 diabetes. PLOS ONE. 2011;6(10):e25792. https://doi.org/10.1371/journal.pone.0025792.

47. Vatanen T, Franzosa EA, Schwager R, et al. The human gut microbiome in early-onset type 1 diabetes from the TEDDY study. Nature. 2018;562(7728):589-94. https://doi.org/10.1038/s41586-018-0620-2.

48. Stewart CJ, Ajami NJ, O'Brien JL, et al. Temporal development of the gut microbiome in early childhood from the TEDDY study. Nature. 2018;562(7728):583-8. https://doi.org/10.1038/s41586-018-0617-x.

49. Uusitalo U, Liu X, Yang J, et al. Association of early exposure of probiotics and islet autoimmunity in the TEDDY study. JAMA Pediatr 2016;170(1):20-8. https://doi.org/10.1001/jamapediatrics.2015.2757.

50. Sohail MU, Althani A, Anwar H, Rizzi R, Marei HE. Role of the gastrointestinal tract microbiome in the pathophysiology of diabetes mellitus. J Diabetes Res. 2017;2017:9631435. https://doi.org/10.1155/2017/96314 35.

51. Meijnikman AS, Gerdes VE, Nieuwdorp M, Herrema H. Evaluating causality of gut microbiota in obesity and diabetes in humans. Endocr Rev. 2018;39(2):133-53. https://doi.org/10.1210/er.2017-00192.

52. Saad MJ, Santos A, Prada PO. Linking gut microbiota and inflammation to obesity and insulin resistance. Physiology (Bethesda). 2016;31(4):283-93. https://doi.org/10.1152/physiol.00041.2015.

53. Falony $\mathrm{G}$, Joossens $\mathrm{M}$, Vieira-Silva $\mathrm{S}$, et al. Population-level analysis of gut microbiome variation. Science. 2016;352(6285):560-4. https://doi. org/10.1126/science.aad3503.

54. Murphy EF, Cotter PD, Healy S, et al. Composition and energy harvesting capacity of the gut microbiota: relationship to diet, obesity and time in mouse models. Gut. 2010;59(12):1635-42. https://doi.org/10. 1136/gut.2010.215665.

55. Jernberg C, Löfmark S, Edlund C, Jansson JK. Long-term ecological impacts of antibiotic administration on the human intestinal microbiota. ISME J. 2007;1 (1):56-66. https://doi.org/10.1038/ismej.2007.3.

56. Mikkelsen KH, Knop FK, Frost M, Hallas J, Pottegård A. Use of antibiotics and risk of type 2 diabetes: a population-based case-control study. J Clin Endocrinol Metab. 2015;100(10):3633-40. https://doi.org/10.1210/ jc.2015-2696.

57. Vrieze A, Out C, Fuentes $S$, et al. Impact of oral vancomycin on gut microbiota, bile acid metabolism, and insulin sensitivity. J Hepatol. 2014;60(4):824-31. https://doi.org/10.1016/j.jhep.2013.11.034.

58. Montandon SA, Jornayvaz FR. Effects of antidiabetic drugs on gut microbiota composition. Genes (Basel). 2017;8(10):250. https://doi.org/ 10.3390/genes8100250.

59. Shin NR, Lee JC, Lee HY, et al. An increase in the Akkermansia spp. population induced by metformin treatment improves glucose homeostasis in diet-induced obese mice. Gut. 2014;63(5):727-35. https://doi.org/10. 1136/gutjnl-2012-303839.

60. Wu H, Esteve E, Tremaroli V, et al. Metformin alters the gut microbiome of individuals with treatment-naive type 2 diabetes, contributing to the therapeutic effects of the drug. Nat Med. 2017;23(7):850-8. https://doi. org/10.1038/nm.4345.

61. Rodriguez J, Hiel S, Delzenne NM. Metformin: old friend, new ways of action-implication of the gut microbiome? Curr Opin Clin Nutr Metab Care. 2018;21(4):294-301. https://doi.org/10.1097/MCO.0000000000 000468 .

62. Sun $L$, Xie C, Wang G, et al. Gut microbiota and intestinal FXR mediate the clinical benefits of metformin. Nat Med. 2018;24(12):1919-29. https://doi.org/10.1038/s41591-018-0222-4.

63. Sheng $Y$, Zheng $S, M a T$, et al. Mulberry leaf alleviates streptozotocininduced diabetic rats by attenuating NEFA signaling and modulating intestinal microflora. Sci Rep. 2017;7(1):12041. https://doi.org/10.1038/ s41598-017-12245-2.

64. van Bommel EJM, Herrema H, Davids M, Kramer MHH, Nieuwdorp M, van Raalte DH. Effects of 12-week treatment with dapagliflozin and gliclazide on faecal microbiome: results of a double-blind randomized trial in patients with type 2 diabetes. Diabetes Metab. 2020;46(2):164-8. https://doi.org/10.1016/j.diabet.2019.11.005.

65. Wang L, Li P, Tang Z, Yan X, Feng B. Structural modulation of the gut microbiota and the relationship with body weight: compared evaluation of liraglutide and saxagliptin treatment. Sci Rep. 2016;6:33251. https://doi.org/10.1038/srep33251.

66. Zhao $L$, Chen Y, Xia F, et al. A glucagon-like peptide-1 receptor agonist lowers weight by modulating the structure of gut microbiota.
Front Endocrinol (Lausanne). 2018;9:233. https://doi.org/10.3389/ fendo.2018.00233.

67. Wang Z, Saha S, Van Horn S, et al. Gut microbiome differences between metformin- and liraglutide-treated T2DM subjects. Endocrinol Diabetes Metab. 2017;1 (1):e00009. https://doi.org/10.1002/ edm2.9.

68. Gérard C, Vidal H. Impact of gut microbiota on host glycemic control. Front Endocrinol (Lausanne). 2019;10:29. https://doi.org/10.3389/ fendo.2019.00029.

69. Roy CC, Kien CL, Bouthillier L, Levy E. Short-chain fatty acids: ready for prime time? Nutr Clin Pract. 2006;21(4):351-66. https://doi.org/10. 1177/0115426506021004351.

70. Mortensen PB, Clausen MR. Short-chain fatty acids in the human colon: relation to gastrointestinal health and disease. Scand J Gastroenterol Suppl. 1996;216:132-48. https://doi.org/10.3109/0036552960 9094568.

71. Ohira $H$, Tsutsui W, Fujioka Y. Are short chain fatty acids in gut microbiota defensive players for inflammation and atherosclerosis? 」 Atheroscler Thromb. 2017;24(7):660-72. https://doi.org/10.5551/jat. RV17006.

72. Dai ZL, Wu G, Zhu WY. Amino acid metabolism in intestinal bacteria: links between gut ecology and host health. Front Biosci (Landmark Ed). 2011;16:1768-86. https://doi.org/10.2741/3820.

73. Macfarlane GT, Allison C, Gibson SA, Cummings JH. Contribution of the microflora to proteolysis in the human large intestine. J Appl Bacteriol. 1988;64(1):37-46. https://doi.org/10.1111/j.1365-2672.1988.tb02427.x.

74. Koh A, De Vadder F, Kovatcheva-Datchary P, Bäckhed F. From dietary fiber to host physiology: short-chain fatty acids as key bacterial metabolites. Cell. 2016;165(6):1332-45. https://doi.org/10.1016/j.cell. 2016.05.041.

75. Cummings $\mathrm{JH}$. Short chain fatty acids in the human colon. Gut. 1981;22(9):763-79. https://doi.org/10.1136/gut.22.9.763.

76. Baxter NT, Lesniak NA, Sinani H, Schloss PD, Koropatkin NM. The glucoamylase inhibitor acarbose has a diet-dependent and reversible effect on the murine gut microbiome. mSphere. 2019;4(1):e00528-e618. https://doi.org/10.1128/mSphere.00528-18.

77. Tazoe H, Otomo Y, Kaji I, Tanaka R, Karaki SI, Kuwahara A. Roles of shortchain fatty acids receptors, GPR41 and GPR43 on colonic functions. J Physiol Pharmacol. 2008;59(Suppl 2):251-62.

78. Tolhurst $\mathrm{G}$, Heffron $\mathrm{H}$, Lam YS, et al. Short-chain fatty acids stimulate glucagon-like peptide-1 secretion via the G-protein-coupled receptor FFAR2. Diabetes. 2012:61(2):364-71. https://doi.org/10.2337/db11-1019.

79. Mandøe MJ, Hansen KB, Hartmann B, Rehfeld JF, Holst JJ, Hansen HS. The 2-monoacylglycerol moiety of dietary fat appears to be responsible for the fat-induced release of GLP-1 in humans. Am J Clin Nutr. 2015;102(3):548-55. https://doi.org/10.3945/ajcn.115.106799.

80. Amato A, Cinci L, Rotondo A, et al. Peripheral motor action of glucagonlike peptide-1 through enteric neuronal receptors. Neurogastroenterol Motil. 2010;22(6):664-e203. https://doi.org/10.1111/j.1365-2982.2010. 01476.x.

81. De Vadder F, Kovatcheva-Datchary P, Goncalves D, et al. Microbiotagenerated metabolites promote metabolic benefits via gut-brain neural circuits. Cell. 2014;156(1-2):84-96. https://doi.org/10.1016/j.cell. 2013.12.016.

82. Al-Lahham SH, Peppelenbosch MP, Roelofsen H, Vonk RJ, Venema K. Biological effects of propionic acid in humans; metabolism, potential applications and underlying mechanisms. Biochim Biophys Acta. 2010;1801(11):1175-83. https://doi.org/10.1016/j.bbalip.2010.07.007.

83. Perry RJ, Peng L, Barry NA, et al. Acetate mediates a microbiomebrain- $\beta$-cell axis to promote metabolic syndrome. Nature. 2016;534(7606):213-7. https://doi.org/10.1038/nature18309.

84. Gao Z, Yin J, Zhang J, et al. Butyrate improves insulin sensitivity and increases energy expenditure in mice. Diabetes. 2009;58(7):1509-17. https://doi.org/10.2337/db08-1637.

85. He J, Zhang P, Shen L, et al. Short-chain fatty acids and their association with signalling pathways in inflammation, glucose and lipid metabolism. Int J Mol Sci. 2020;21(17):6356. https://doi.org/10.3390/ijms211763 56.

86. Salminen S, Bouley C, Boutron-Ruault MC, et al. Functional food science and gastrointestinal physiology and function. Br J Nutr. 1998;80(Suppl 1):S147-71. https://doi.org/10.1079/bjn19980108. 
87. Frost G, Sleeth ML, Sahuri-Arisoylu M, et al. The short-chain fatty acid acetate reduces appetite via a central homeostatic mechanism. Nat Commun. 2014;5:3611. https://doi.org/10.1038/ncomms4611.

88. Hamer HM, Jonkers D, Venema K, Vanhoutvin S, Troost FJ, Brummer RJ. Review article: the role of butyrate on colonic function. Aliment Pharmacol Ther. 2008;27(2):104-19. https://doi.org/10.1111/j.1365-2036. 2007.03562.x.

89. Sanna S, van Zuydam NR, Mahajan A, et al. Causal relationships among the gut microbiome, short-chain fatty acids and metabolic diseases. Nat Genet. 2019;51(4):600-5. https://doi.org/10.1038/ s41588-019-0350-x

90. den Besten G, Lange K, Havinga R, et al. Gut-derived short-chain fatty acids are vividly assimilated into host carbohydrates and lipids. Am J Physiol Gastrointest Liver Physiol. 2013;305(12):G900-10. https://doi. org/10.1152/ajpgi.00265.2013.

91. Bloemen JG, Olde Damink SW, Venema K, Buurman WA, Jalan R, Dejong $\mathrm{CH}$. Short chain fatty acids exchange: Is the cirrhotic, dysfunctional liver still able to clear them? Clin Nutr. 2010;29(3):365-9. https://doi.org/10. 1016/j.clnu.2009.10.002.

92. Pingitore A, Chambers ES, Hill T, et al. The diet-derived short chain fatty acid propionate improves beta-cell function in humans and stimulates insulin secretion from human islets in vitro. Diabetes Obes Metab. 2017;19(2):257-65. https://doi.org/10.1111/dom.12811.

93. Chambers ES, Viardot A, Psichas A, et al. Effects of targeted delivery of propionate to the human colon on appetite regulation, body weight maintenance and adiposity in overweight adults. Gut. 2015;64(11):1744-54. https://doi.org/10.1136/gutjnl-2014-307913.

94. Zhao L, Zhang F, Ding $X$, et al. Gut bacteria selectively promoted by dietary fibers alleviate type 2 diabetes. Science. 2018;359(6380):1151-6. https://doi.org/10.1126/science.aao5774.

95. Vitale M, Giacco R, Laiola M, et al. Acute and chronic improvement in postprandial glucose metabolism by a diet resembling the traditional Mediterranean dietary pattern: can SCFAs play a role? Clin Nutr. 2021;40(2):428-37. https://doi.org/10.1016/j.clnu.2020.05.025.

96. De Vadder F, Kovatcheva-Datchary P, Zitoun C, Duchampt A, Bäckhed F, Mithieux G. Microbiota-produced succinate improves glucose homeostasis via intestinal gluconeogenesis. Cell Metab. 2016;24(1):151-7. https://doi.org/10.1016/j.cmet.2016.06.013.

97. Venter CS, Vorster HH, Cummings JH. Effects of dietary propionate on carbohydrate and lipid metabolism in healthy volunteers. Am J Gastroenterol. 1990;85(5):549-53.

98. Wang TJ, Larson MG, Vasan RS, et al. Metabolite profiles and the risk of developing diabetes. Nat Med. 2011;17(4):448-53. https://doi.org/10. 1038/nm.2307.

99. Chimerel C, Emery E, Summers DK, Keyser U, Gribble FM, Reimann F. Bacterial metabolite indole modulates incretin secretion from intestinal enteroendocrine L cells. Cell Rep. 2014;9(4):1202-8. https://doi.org/10. 1016/j.celrep.2014.10.032.

100. Gribble FM, Reimann F. Function and mechanisms of enteroendocrine cells and gut hormones in metabolism. Nat Rev Endocrinol. 2019;15(4):226-37. https://doi.org/10.1038/s41574-019-0168-8.

101. Koh A, Molinaro A, Ståhlman M, et al. Microbially produced imidazole propionate impairs insulin signaling through mTORC1. Cell. 2018;175(4):947-961.e17. https://doi.org/10.1016/j.cell.2018.09.055.

102. Swann JR, Want EJ, Geier FM, et al. Systemic gut microbial modulation of bile acid metabolism in host tissue compartments. Proc Natl Acad Sci U S A. 2011;108(Suppl 1):4523-30. https://doi.org/10.1073/pnas. 1006734107.

103. Sayin SI, Wahlström A, Felin J, et al. Gut microbiota regulates bile acid metabolism by reducing the levels of tauro-beta-muricholic acid, a naturally occurring FXR antagonist. Cell Metab. 2013;17(2):225-35. https://doi.org/10.1016/j.cmet.2013.01.003.

104. Lazar V, Ditu LM, Pircalabioru GG, et al. Gut microbiota, host organism, and diet trialogue in diabetes and obesity. Front Nutr. 2019;6:21. https:// doi.org/10.3389/fnut.2019.00021.

105. Thomas C, Gioiello A, Noriega L, et al. TGR5-mediated bile acid sensing controls glucose homeostasis. Cell Metab. 2009;10(3):167-77. https:// doi.org/10.1016/j.cmet.2009.08.001.

106. Kurdi P, Kawanishi K, Mizutani K, Yokota A. Mechanism of growth inhibition by free bile acids in lactobacilli and bifidobacteria. J Bacteriol. 2006;188(5):1979-86. https://doi.org/10.1128/JB.188.5.1979-1986.2006.
107. Nicholson JK, Holmes E, Kinross J, et al. Host-gut microbiota metabolic interactions. Science. 2012;336(6086):1262-7. https://doi.org/10.1126/ science.1223813.

108. Yamagata K, Daitoku H, Shimamoto $Y$, et al. Bile acids regulate gluconeogenic gene expression via small heterodimer partner-mediated repression of hepatocyte nuclear factor 4 and Foxo1. J Biol Chem. 2004:279(22):23158-65. https://doi.org/10.1074/jbc.M314322200.

109. Kir S, Beddow SA, Samuel VT, et al. FGF19 as a postprandial, insulinindependent activator of hepatic protein and glycogen synthesis. Science. 2011;331(6024):1621-4. https://doi.org/10.1126/science.11983 63.

110. Cicione C, Degirolamo C, Moschetta A. Emerging role of fibroblast growth factors 15/19 and 21 as metabolic integrators in the liver. Hepatology. 2012;56(6):2404-11. https://doi.org/10.1002/hep.25929.

111. Potthoff MJ, Kliewer SA, Mangelsdorf DJ. Endocrine fibroblast growth factors 15/19 and 21: from feast to famine. Genes Dev. 2012;26(4):31224. https://doi.org/10.1101/gad.184788.111.

112. Sonne DP, Hansen M, Knop FK. Bile acid sequestrants in type 2 diabetes: potential effects on GLP1 secretion. Eur J Endocrinol. 2014;171(2):R4765. https://doi.org/10.1530/EJE-14-0154.

113. Hansen M, Sonne DP, Knop FK. Bile acid sequestrants: glucoselowering mechanisms and efficacy in type 2 diabetes. Curr Diab Rep. 2014;14(5):482. https://doi.org/10.1007/s11892-014-0482-4.

114. Hartmann P, Chen P, Wang HJ, et al. Deficiency of intestinal mucin-2 ameliorates experimental alcoholic liver disease in mice. Hepatology. 2013;58(1):108-19. https://doi.org/10.1002/hep.26321.

115. Everard A, Cani PD. Diabetes, obesity and gut microbiota. Best Pract Res Clin Gastroenterol. 2013;27(1):73-83. https://doi.org/10.1016/j.bpg. 2013.03.007.

116. Cani PD, Possemiers S, Van de Wiele T, et al. Changes in gut microbiota control inflammation in obese mice through a mechanism involving GLP-2-driven improvement of gut permeability. Gut. 2009;58(8):1091103. https://doi.org/10.1136/gut.2008.165886.

117. Hansen J, Gulati A, Sartor RB. The role of mucosal immunity and host genetics in defining intestinal commensal bacteria. Curr Opin Gastroenterol. 2010;26(6):564-71. https://doi.org/10.1097/MOG.0b013e3283 3 f1195.

118. Dandona P, Aljada A, Bandyopadhyay A. Inflammation: the link between insulin resistance, obesity and diabetes. Trends Immunol. 2004;25(1):47. https://doi.org/10.1016/j.it.2003.10.013.

119. Reyes M, Quintanilla C, Burrows R, Blanco E, Cifuentes M, Gahagan S. Obesity is associated with acute inflammation in a sample of adolescents. Pediatr Diabetes. 2015;16(2):109-16. https://doi.org/10.1111/ pedi.12129.

120. Delzenne NM, Cani PD, Everard A, Neyrinck AM, Bindels LB. Gut microorganisms as promising targets for the management of type 2 diabetes. Diabetologia. 2015;58(10):2206-17. https://doi.org/10.1007/ s00125-015-3712-7.

121. Devaraj $S$, Hemarajata P, Versalovic J. The human gut microbiome and body metabolism: implications for obesity and diabetes. Clin Chem. 2013:59(4):617-28. https://doi.org/10.1373/clinchem.2012.187617.

122. Ley RE. Obesity and the human microbiome. Curr Opin Gastroenterol. 2010;26(1):5-11. https://doi.org/10.1097/MOG.0b013e328333d751.

123. Cani $P D$, Bibiloni $R$, Knauf $C$, et al. Changes in gut microbiota control metabolic endotoxemia-induced inflammation in high-fat diet-induced obesity and diabetes in mice. Diabetes. 2008;57(6):1470-81. https://doi. org/10.2337/db07-1403.

124. Chen X, Devaraj S. Gut microbiome in obesity, metabolic syndrome, and diabetes. Curr Diab Rep. 2018;18(12):129. https://doi.org/10.1007/ s11892-018-1104-3.

125. Rakoff-Nahoum S, Paglino J, Eslami-Varzaneh F, Edberg S, Medzhitov R. Recognition of commensal microflora by toll-like receptors is required for intestinal homeostasis. Cell. 2004;118(2):229-41. https://doi.org/10. 1016/j.cell.2004.07.002.

126. Li X, Watanabe K, Kimura I. Gut microbiota dysbiosis drives and implies novel therapeutic strategies for diabetes mellitus and related metabolic diseases. Front Immunol. 2017;8:1882. https://doi.org/10.3389/fimmu. 2017.01882.

127. Grabstein KH, Eisenman J, Shanebeck K, et al. Cloning of a T cell growth factor that interacts with the beta chain of the interleukin-2 receptor. 
Science. 1994;264(5161):965-8. https://doi.org/10.1126/science.81781 55.

128. Sun H, Liu D. Hydrodynamic delivery of interleukin 15 gene promotes resistance to high fat diet-induced obesity, fatty liver and improves glucose homeostasis. Gene Ther. 2015;22(4):341-7. https://doi.org/10. 1038/gt.2014.114

129. Barra NG, Reid S, Mackenzie R, et al. Interleukin-15 contributes to the regulation of murine adipose tissue and human adipocytes. Obesity (Silver Spring). 2010;18(8):1601-7. https://doi.org/10.1038/oby.2009. 445.

130. Rui L, Yuan M, Frantz D, Shoelson S, White MF. SOCS-1 and SOCS-3 block insulin signaling by ubiquitin-mediated degradation of IRS1 and IRS2. J Biol Chem. 2002;277(44):42394-8. https://doi.org/10.1074/jbc.C2004 44200.

131. Zhao L. The gut microbiota and obesity: from correlation to causality. Nat Rev Microbiol. 2013;11(9):639-47. https://doi.org/10.1038/nrmic ro3089.

132. Kim M, Qie Y, Park J, Kim CH. Gut microbial metabolites fuel host antibody responses. Cell Host Microbe. 2016;20(2):202-14. https://doi.org/ 10.1016/j.chom.2016.07.001

133. Donath MY. Targeting inflammation in the treatment of type 2 diabetes: time to start. Nat Rev Drug Discov. 2014;13(6):465-76. https://doi.org/ 10.1038/nrd4275.

134. Larsen CM, Faulenbach M, Vaag A, et al. Interleukin-1-receptor antagonist in type 2 diabetes mellitus. N Engl J Med. 2007;356(15):1517-26. https://doi.org/10.1056/NEJMoa065213.

135. Pradhan AD, Manson JE, Rifai N, Buring JE, Ridker PM. C-reactive protein, interleukin 6, and risk of developing type 2 diabetes mellitus. JAMA. 2001;286(3):327-34. https://doi.org/10.1001/jama.286.3.327.

136. Rotter V, Nagaev I, Smith U. Interleukin-6 (IL-6) induces insulin resistance in 3T3-L1 adipocytes and is, like IL-8 and tumor necrosis factor-alpha, overexpressed in human fat cells from insulin-resistant subjects. J Biol Chem. 2003;278(46):45777-84. https://doi.org/10.1074/jbc.M3019 77200.

137. Salgaço MK, Oliveira LGS, Costa GN, Bianchi F, Sivieri K. Relationship between gut microbiota, probiotics, and type 2 diabetes mellitus. Appl Microbiol Biotechnol. 2019;103(23-24):9229-38. https://doi.org/10. 1007/s00253-019-10156-y.

138. Panwar H, Rashmi HM, Batish VK, Grover S. Probiotics as potential biotherapeutics in the management of type 2 diabetes - prospects and perspectives. Diabetes Metab Res Rev. 2013;29(2):103-12. https://doi. org/10.1002/dmrr.2376.

139. Hill C, Guarner F, Reid G, et al. Expert consensus document. The International Scientific Association for Probiotics and Prebiotics consensus statement on the scope and appropriate use of the term probiotic. Nat Rev Gastroenterol Hepatol. 2014;11 (8):506-14. https://doi.org/10.1038/ nrgastro.2014.66.

140. Louis P, Flint HJ, Michel C. How to manipulate the microbiota: prebiotics. Adv Exp Med Biol. 2016;902:119-42. https://doi.org/10.1007/ 978-3-319-31248-4_9.

141. Swanson KS, Gibson GR, Hutkins R, et al. The International Scientific Association for Probiotics and Prebiotics (ISAPP) consensus statement on the definition and scope of synbiotics. Nat Rev Gastroenterol Hepatol. 2020;17(11):687-701. https://doi.org/10.1038/s41575-020-0344-2.

142. Balakumar M, Prabhu D, Sathishkumar C, et al. Improvement in glucose tolerance and insulin sensitivity by probiotic strains of Indian gut origin in high-fat diet-fed C57BL/6J mice. Eur J Nutr. 2018;57(1):279-95. https://doi.org/10.1007/s00394-016-1317-7.
143. Tao YW, Gu YL, Mao XQ, Zhang L, Pei YF. Effects of probiotics on type II diabetes mellitus: a meta-analysis. J TransI Med. 2020;18(1):30. https:// doi.org/10.1186/s12967-020-02213-2.

144. Andreasen AS, Larsen N, Pedersen-Skovsgaard T, et al. Effects of Lactobacillus acidophilus NCFM on insulin sensitivity and the systemic inflammatory response in human subjects. Br J Nutr. 2010;104(12):1831-8. https://doi.org/10.1017/S0007114510002874.

145. Firouzi S, Majid HA, Ismail A, Kamaruddin NA, Barakatun-Nisak MY. Effect of multi-strain probiotics (multi-strain microbial cell preparation) on glycemic control and other diabetes-related outcomes in people with type 2 diabetes: a randomized controlled trial. Eur J Nutr. 2017;56(4):1535-50. https://doi.org/10.1007/s00394-016-1199-8.

146. Wang $\mathrm{L}$, Yang $\mathrm{H}$, Huang $\mathrm{H}$, et al. Inulin-type fructans supplementation improves glycemic control for the prediabetes and type 2 diabetes populations: results from a GRADE-assessed systematic review and dose-response meta-analysis of 33 randomized controlled trials. J Transl Med. 2019;17(1):410. https://doi.org/10.1186/s12967-019-02159-0.

147. Birkeland E, Gharagozlian S, Birkeland Kl, et al. Prebiotic effect of inulintype fructans on faecal microbiota and short-chain fatty acids in type 2 diabetes: a randomised controlled trial. Eur J Nutr. 2020;59(7):3325-38. https://doi.org/10.1007/s00394-020-02282-5.

148. Pedersen C, Gallagher E, Horton F, et al. Host-microbiome interactions in human type 2 diabetes following prebiotic fibre (galacto-oligosaccharide) intake. Br J Nutr. 2016;116(11):1869-77. https://doi.org/10. 1017/S0007114516004086.

149. Sheth M, Chand V, Thakuria A. Inflated levels of SCFA, Bifidobacteria and Lactobacillus improves the status of pre hypertension and type 2 diabetes mellitus in subjects residing in north east India—a randomized control trial with synbiotic supplementation. Int J Curr Pharm Res. 2015;7:33-6.

150. Allegretti JR, Kassam Z, Osman M, Budree S, Fischer M, Kelly CR. The 5D framework: a clinical primer for fecal microbiota transplantation to treat Clostridium difficile infection. Gastrointest Endosc. 2018;87(1):18-29. https://doi.org/10.1016/j.gie.2017.05.036.

151. Tariq R, Pardi DS, Bartlett MG, Khanna S. Low cure rates in controlled trials of fecal microbiota transplantation for recurrent Clostridium difficile infection: a systematic review and meta-analysis. Clin Infect Dis. 2019;68(8):1351-8. https://doi.org/10.1093/cid/ciy721.

152. Lee P, Yacyshyn BR, Yacyshyn MB. Gut microbiota and obesity: an opportunity to alter obesity through faecal microbiota transplant (FMT). Diabetes Obes Metab. 2019;21(3):479-90. https://doi.org/10. 1111/dom.13561

153. Vrieze A, Van Nood E, Holleman F, et al. Transfer of intestinal microbiota from lean donors increases insulin sensitivity in individuals with metabolic syndrome. Gastroenterology. 2012;143(4):913-6.e7. https://doi. org/10.1053/j.gastro.2012.06.031.

154. Kootte RS, Levin E, Salojärvi J, et al. Improvement of insulin sensitivity after lean donor feces in metabolic syndrome is driven by baseline intestinal microbiota composition. Cell Metab. 2017;26(4):611-619.e6. https://doi.org/10.1016/j.cmet.2017.09.008.

\section{Publisher's Note}

Springer Nature remains neutral with regard to jurisdictional claims in published maps and institutional affiliations. 